\title{
THE IMPACT OF SUPPLY CHAIN STRUCTURE ON THE USE OF SUPPLIER SOCIALLY RESPONSIBLE PRACTICES
}

Forthcoming in the International Journal of Operations and Production Management

\author{
Amrou Awaysheh* \\ Assistant Professor of Operations Management \\ amrou.awaysheh@ie.edu \\ Instituto de Empresa (IE Business School) \\ Maria de Molina, 12, 5 Planta \\ Madrid, 28006 Spain \\ Robert D. Klassen \\ Professor of Operations Management \\ J.J. Wettlaufer Faculty Fellow \\ rklassen@ivey.uwo.ca \\ Richard Ivey School of Business \\ University of Western Ontario \\ 1151 Richmond Street \\ London, Ontario N6A 3K7 Canada \\ * corresponding author
}

This is the authors' manuscript of the work published in final form as:

Awaysheh, A., \& Klassen, R. D. (2010). The impact of supply chain structure on the use of supplier socially responsible practices. International Journal of Operations \& Production Management, 30(12), 1246-1268. https://doi.org/10.1108/01443571011094253 


\begin{abstract}
Purpose - This paper explores the integration of social issues in the management of supply chains from an operations management perspective. Further, this research develops a set of scales to measure multiple dimensions of supplier socially responsible practices. Finally, the paper examines the importance of three dimensions of supply chain structure, namely transparency, dependency and distance, for the adoption of these socially responsible practices.
\end{abstract}

Methodology / approach - Drawing on literature from several theoretical streams, current bestpractice in leading firms and emerging international standards, four dimensions of supplier socially responsible practices were identified. Also, a multi-dimensional conceptualization of supply chain structure, including transparency, dependency and distance, was synthesized from earlier research. Using this conceptual development, a large-scale survey of plant managers in three industries in Canada provided an empirical basis for validating these constructs, and then assessing the relationships between structure and practices.

Findings - Multi-item scales for each of the four dimensions of supplier socially responsible practices were validated empirically: supplier human rights; supplier labour practices; supplier codes of conduct; and supplier social audits. Increased transparency, as reflected in greater product visibility by the end-consumer was related to increased use of supplier human rights, which in turn can help to protect a firm's brands. Organizational distance, as measured by the total length of the supply chain (number of tiers in the supply chain), was related to increased use of multiple supplier socially responsible practices. Finally, as the plant was positioned further upstream in the supply chain, managers reported increased use of supplier codes of conduct.

Research limitations / implications - This research focused on larger plants in three manufacturing industries in a single developed country. As social pressures can vary by the location of the end-consumer, it is possible that relationships might vary from developing to developed economies, as well as within different political settings.

Practical implications - As senior managers extend, redesign or restructure their supply chains, the extent to which social issues must be monitored and managed changes. The four categories of supplier socially responsible practices identified help managers characterize their firm's approach to managing social issues. Furthermore, managers must more actively manage the development of supplier socially responsible practices in their firms when the supply chain has more firms; and when brands have stronger recognition in the marketplace.

Keywords: Corporate social performance; supplier labour practices; supply chain management, fair trade practices. 


\section{INTRODUCTION}

As technology improves the transfer of information, a broader range of customers and stakeholders gain access to more information about what happens within supply chains. As a result, issues like poor worker conditions in suppliers' facilities are increasingly pushed into the limelight. What used to be hidden years ago behind long distances and language differences has become quite visible via 24-hour cable news and videos that are captured using cell phones - not unlike the enhanced ability of companies to capture information about their suppliers (Lee, 2002; Van Der Zee and Van Der Vorst, 2005). As a result, consumers, governments, and nongovernmental organizations (NGOs) are demanding that companies be held more accountable for what happens in their supply chains. Concerns include the use of sweatshop labour, the provision of safe working conditions, and the payment of a living wage to their employees.

In response, a growing number of firms are exploring how to identify, assess, and monitor supplier-related social issues and practices. For example, firms can monitor their suppliers to ensure adherence to social expectations, conduct audits, or use a certification provided by an independent third-party. Fairtrade (Fairtrade, 2007) is one such third-party certification for agricultural commodities such as coffee and cocoa beans. Following an audit, certification is granted to cooperative farms in developing countries that adhere to a number of sustainabilityrelated principles, including safe working conditions for employees, payment of fair wages, and environmentally friendly cultivation techniques. In contrast, other firms choose to develop their own standards internally, for example Starbucks' system for assessing and working with farmers, termed Coffee and Farmer Equity (CAFE). 
Unfortunately, it is not as simple as just dictating that a particular set of standards be employed by every supplier to the plant or firm. First, some firms might not have sufficient influence to drive change back through the supply chain to all suppliers. Second, the cultural norms and expectations for improving human potential vary by industry, customer segment, and marketplace. Third, as more manufacturing and supplier sourcing has shifted overseas, the geographic distance, and length of supply chains (i.e., tiers) between supply chain partners also has increased. Furthermore, the costs associated with adoption practices to deal with social issues might be prohibitive. So overall, much remains unclear about how the structure of the supply chain influences the management of social issues between a focal firm and its suppliers.

The overarching objective of this paper is to identify the factors that can influence firms to engage in specific supplier socially responsible practices, and how these factors influence the adoption of these practices. Thus, this paper makes three contributions to the extant literature. First, the construct of social issues is defined and framed within the broader debate on sustainable development and stakeholder management. Second, social practices are delineated for supply chain management, and a set of scales is empirically validated for assessing the degree of development of supplier socially responsible practices. Finally, the link between supply chain structure and the adoption of supplier socially responsible practices is examined. This last contribution provides a basis for understanding, so that managers can extend and reshape current views about how social issues must be managed.

\section{DEFINING SOCIAL ISSUES}

Sustainable development, generally defined as "meeting the needs of the present without compromising the ability of future generations to meet their own needs" (Brundtland, 1987, pp. 
1) implies that a broad and complex range of issues must be actively managed by firms. One lens through which to operationalize this concept for operations and supply chain management research is the Triple Bottom Line (TBL) (Elkington, 1997; Carter and Rogers, 2008), encompassing environmental and social performance, in addition to financial performance. Environmental management and performance has received a growing degree of attention in the operations literature, including such areas as green product design (Baumann et al., 2002), closed loop supply chains, and green supplier development (a detailed literature review is provided by Seuring and Müller (2008)).

Social issues and performance capture both individual-level human safety and welfare, and societal-level community development. Thus, by extension, social practices and performance in operations and the supply chain encompass all management practices that affect how a firm contributes to the development of human potential or protects people from harm, thereby capturing both positive and negative aspects, respectively. Examples include workforce policies for safety or diversity, and product safety. While corporate philanthropy might also be viewed as social performance (Porter and Kramer, 2006), it will not be considered further in this paper, as that lies beyond the control of operations and supply chain managers.

Societal expectations for acceptable practices and standards of conduct continue to evolve and ratchet upwards as public opinion, NGOs, the popular press, and regulations uncover shortcomings in previously acceptable routines (Martin, 2002). Supply chain members, particularly customers, also apply pressure to firms to improve in areas where problems or inconsistent social practices become apparent, such as suppliers' treatment of their workers in developing economies (Carter, 2000). Thus, for operations, a mid-range definition of supplier 
socially responsible practices is critical to structuring research. Thus, further research is needed to identify tools, systems and programs that operations can put in place to assess and monitor the degree to which social issues are managed by their suppliers, and ideally, improve performance.

\section{Managing Social Issues in the Supply Chain}

Three major streams of study help to organize our understanding of social issues in the supply chain: international labour practice standards; socially responsible purchasing; and parallels between environmental and social auditing. First, firms with international supply chains reaching into developing countries have increasingly adopted standards, such as SA8000, that set basic requirements for workforce practices in internal operations and in multiple tiers of suppliers (Social Accountability International, 2008). Nine areas are explicitly examined, including child labour; forced labour; health and safety; freedom of association and collective bargaining; discrimination; disciplinary practices; working hours; compensation; and related management systems. A related standard, ISO 26000, remains in development, and is expected to parallel environmental management standard, ISO 14001 (Castka and Balzarova, 2008).

In contrast, reporting frameworks like the Global Reporting Initiative (GRI) provide a means for companies to identify, structure, and communicate their triple bottom line performance to stakeholders both inside and outside the firm (GRI, 2006). In addition to required key indicators, others are developed in consultation with stakeholders. However, the objectives can vary quite significantly between different standards and frameworks, with some focusing on societal expectations, e.g., not using child labour, and others on improved working conditions, e.g., paying over-time for additional work (Jantzi, 2008). 
Second, socially responsible purchasing has been based on the deployment of firm- or industryspecific codes of conduct (COC). COC dictate specific guidelines, behaviors, and buying criteria that employees in the purchasing department or supply chain group must follow during their interactions with potential and current suppliers (Mamic, 2005). In addition, COC can be used as leverage to encourage change in, or in the worst cases termination of, contracts with suppliers that were found to violate social expectations (Emmelhainz and Adams, 1999).

More recently, Carter and Jennings (2002) have extended this work and proposed a multidimensional index to operationalize socially responsible purchasing, including environment, diversity, safety, human rights, and philanthropy. While the index a much needed step in the right direction, it captures more than just social practices, including such aspects as environmental management and philanthropy. In contrast, focusing on COC provides a clearer view of specific measurable elements within the firm.

The third stream focuses on social auditing, and borrows heavily from research in environmental management. Operations can either monitor or collaborate with its suppliers to assess and improve performance, respectively (Zhao et al., 2007). With monitoring, either the firm or a third-party physically inspects the operations of first- or second-tier suppliers to ensure that specific practices are being used. These audits go well beyond quality and other supplier performance criteria that have been in place for many years, and thus represent a significant, incremental investment and commitment (Krause, 1999). Subsequent to inspection and auditing, a firm may undertake collaboration to work with supply chain partners to enable the development of new skills and capabilities (Klassen and Vachon, 2003). 
Collectively, the three streams point toward four broad categories of supplier socially responsible practices. International standards that seek to ensure supplier human rights are being protected, extended frameworks that capture supplier labour practices, supplier Codes of Conduct (COC) that structure how a firm should interact with its supply chain partners, and finally, supplier social audits that seek to ensure human rights and labour practices are being adhered to.

\section{SUPPLY CHAIN STRUCTURE}

Operations managers must consider many factors when designing, developing and restructuring their supply chains as markets evolve. Moreover, social practices for suppliers do not develop in isolation, but instead must be connected with, and take into account, the nature of both the upstream and downstream portions of the supply chain. And at a minimum, the location of suppliers and the forms of interaction between supply chain members have important social implications, and cannot be ignored. Thus, three dimensions relating to the structure of the supply chain were identified as potentially having a significant impact on the tools, systems and programs that are in place to address social issues with suppliers: transparency, dependency and distance.

\section{Transparency}

When considered within the context of supply chains, transparency captures the extent to which information is readily available to end-users and other firms in the supply chain. Transparency has become increasingly important for social issues, including the origins of commodities (i.e., provenance) and product safety (Lee, 2002; Van Der Zee and Van Der Vorst, 2005). For example, supply chain provenance tracks products from raw material sourcing to supply chain partners, to manufacturing, to distribution, and to end-consumer use (and beyond, if needed). 
Organic foods and "conflict" diamonds are but a few labels that require all supply chain partners to ensure traceability of goods (New, 2004).

Legitimacy is enhanced if third-party standards and independent auditors are employed, such as SA8000 or Fairtrade certification (Bansal and Hunter, 2003). An alternative is pre-qualification or direct audit of suppliers against a specific set of social standards established internally by the firm itself (Settings, 2004). Nike, for example, has developed its own standards for workforce and environmental practices using input from a variety of stakeholder groups. Third-parties might then assist with monitoring suppliers for compliance with these standards, although fulfillment is not necessarily assured because information remains difficult to verify (Nike, 2004).

Large firms with highly visible brand names might be expected to actively work to guard against unexpected criticism of social performance in their supply chain, which in turn can harm the value of their brands. Moreover, the internet encourages rapid dissemination of negative information, and customers will react quickly after questionable behavior is identified (Tapscott and Ticoll, 2003). Thus, the degree to which supply chains are transparent and subject to scrutiny by NGOs, the media and the public is likely to influence the extent to which a firm actively develops supplier socially responsible practices (Graafland, 2002).

H1: As the level of transparency in the supply chain increases, the firm's use of supplier socially responsible practices increases.

\section{Dependency}

The dependency dimension represents the degree to which a firm relies on other members of the supply chain for critical resources, components, or capabilities. For supply chains, several 
factors affect the degree of dependency, including concentration, vertical integration, and credible commitment (Cool and Henderson, 1998). Each of these factors facilitates a firm's ability to control and influence change in the operations of its suppliers, and they extend beyond simple pricing power (i.e., the continual drive to force prices down) to encompass multiple aspects of the buyer-supplier relationship. Moreover, a focal firm can potentially transfer responsibilities for, and pressures to improve, social issues away from itself to either upstream or downstream partners in the supply chain through rewards, coercion, or legal instruments, to name several means (Maloni and Benton, 2000). Naturally, having power to transfer responsibility implies a corresponding imbalance in dependency, and it can be a factor either upstream or downstream in the supply chain, i.e., the focal firm's dependency on its suppliers or customers, respectively.

Greater competition and fragmentation in markets increase a focal firm's dependency on supply chain partners. Dependency theory (Pfeffer and Salancik, 1978) also suggests that power, and ultimately profitability, decrease for a buying firm as the number of potential suppliers falls. Furthermore, credible commitment also is likely to decrease. Credible commitment, a concept borrowed from game theory, captures the believability of the focal firm's assurances (positive or negative) about the actions that the firm will take in response to specific behaviours or outcomes of a supplier. Thus, signaling by a focal firm is less likely to alter suppliers' priorities and actions if the firm is highly dependent on suppliers (Dixit and Nalebuff, 1991). Collectively, these outcomes arise because few alternative supply arrangements are available for a focal firm.

In contrast, firms that are vertically integrated tend to have greater information about products, processes and markets, which provides leverage in negotiations with their supply base (Harrigan, 
1985) and affects supplier involvement in product development (Carr et al., 2008). Applied to social issues, a vertically integrated focal firm knows the workings of the industry (i.e., what is practically achievable), can lead by example, and can force suppliers to report about such aspects as workforce practices. However, such reporting is unlikely to occur if the firm is highly dependent; the ability to adopt and enforce supplier socially responsible practices is very limited, at best.

H2a: As the dependency of the focal firm on its suppliers increases, the firm's use of supplier socially responsible practices decreases.

Turning upstream, in an industry where a focal firm confronts intense competition, such a firm might attempt to differentiate itself by engaging in socially responsible practices, possibly as a means of offering enhanced value with its products. Furthermore, firms who are highly dependent on customers also might be viewed as an easy target by NGOs, downstream customers, and the general public to be pushed to improve workforce conditions in their suppliers - thereby becoming an example for competitors (e.g. Grow, 2005). Thus, the effects of dependency are not expected to be symmetrical, with customer dependency stimulating the use of supplier socially responsible practices, and supplier dependency dampening their development.

H2b: As the dependency of the focal firm on its customers increases, the firm's use of supplier socially responsible practices increases.

\section{Distance}

If a firm uses local suppliers to serve local customers, the need to use a variety of supplier socially responsible practices is dramatically reduced, as all three can be expected in move in tandem. However, as the distance increases, managers confront problems in data gathering, 
assessment and implementation (Klassen and Vachon, 2003). Distance encompasses three subdimensions: geographical, cultural, and organizational distance. First, as geographical separation expands, firms have more difficulty interacting frequently with their suppliers (Choy and Lee, 2003), and by extension, ensuring good working conditions are maintained. In addition, either the supplier or distant focal firm may view the other party as having less commitment. As a result, firms facing the challenge of geographic distance may feel compelled to establish monitoring or auditing systems to help mitigate shortcomings derived from limited access to information and uncertain commitment (Koplin et al., 2007).

Second, cultural distance reflects the differences that exist between the cultures of the societies in which the firms are based (Hofstede, 1980). Cultural distance influences the approaches that managers choose when confronting new or challenging problems (Joynt and Warner, 1996), as well as relationships between firms (Reynolds et al., 2003). If focal firms and their suppliers are based in societies with similar cultures, discussions about expectations and possible changes to operations are straightforward as managers in both organizations draw from similar cultural experiences. Moreover, regulatory frameworks and expectations, including enforcement, in each jurisdiction are likely to be similar. Thus, potential misunderstandings and problems can be avoided (Hofstede, 2001). In contrast, if the focal firm is located in a developed country and sources from developing countries, it must conform to cultural expectations (and regulations) in its own local market (O'Grady and Lane, 1996), which may not understood by suppliers. Finally, managers of firms operating in countries with democratic institutions and a free press are aware that improper or deficient practices are more likely to become public knowledge. However, this may be of little concern to particular suppliers. 
Third, organizational distance is defined by the number of tiers that exist between the focal firm and suppliers or customers, and the length of the supply chain (Banet, 1976). Increasing organizational distance tends to increase complexity with more frequent hand-offs of information in such areas as product tracing, material specification, and operational procedures. Longer supply chains also potentially increase the number of relationships that might be managed. Thus, increased organizational distance between firms necessitates that additional mechanisms must be put in place, generating higher total transaction costs across the supply chain (Williamson, 1979; Grover and Malhotra, 2003). It should be stressed that the three forms of distance are not necessarily highly correlated. For example, a firm in Europe might source from either Brazil or Thailand, both roughly equivalent in geographic distance, but very different in cultural distance.

Collectively, as the distance in the supply chain increases, a focal firm is more likely to develop a stronger set of supplier socially responsible practices to manage the distance, differences in culture and inter-organizational complexity.

H3: As distance increases in a supply chain, a firm's use of supplier socially responsible practices increases.

The basic construct dimensions of supply chain structure and supplier socially responsible practices are depicted in Figure 1.

Insert Figure 1 here

\section{RESEARCH METHODOLOGY}

\section{Sample}

The relationship between the structure of the supply chain and supplier socially responsible practices was explored using a plant-level survey. An ideal set of industries for this research has 
several characteristics: high degree of variation in approaches to managing social issues, a competitive marketplace to ensure at least some responsiveness to multiple stakeholders, and a multiplicity of different structures for their supply chains. The last criterion points to the need to capture supply chains that reach into both developing and developed economies, encompass a range of social concerns, and have different production technologies (e.g., process vs. discrete product). In addition, if an industry is facing some pressure for change in their management of social issues, whether driven by regulation, public pressure or customer demands, some firms are likely to lead the industry with innovative or proactive initiatives, while others "wait and see" or even resist changes. Based on these criteria, three industries were selected: food (North American Industrial Classification System (NAICS) code 311), chemicals (NAICS 325), and transportation equipment (NAICS 336). Each of these industries is very competitive, is facing evolving social pressures, and has supply chains that span from local to global networks.

The targeted respondent for the survey also was carefully considered. First, it was important to focus on one well-defined individual in a firm, as it was impractical to expect multiple managers across many firms to respond to a lengthy survey instrument. Second, this person must be intimately involved in managing internal operations, the supply chain, and ideally, the surrounding community. Rather than targeting either a senior supply chain manager (who often focuses only on either the upstream or downstream portion of the supply chain) or a corporate staff person (who can be rather disconnected from day-to-day operations), this research targeted the plant manager. In many ways, this individual becomes the nexus for many social issues in the supply chain. Internal operations clearly are under her or his responsibility, and the plant is intimately connected to both upstream suppliers for incoming parts and downstream customers for outgoing products. Moreover, approaches to social issues can vary between plants, even 
within the same firm, depending on the network of suppliers used and customers served. One concern could be raised as to how many of the respondents were actually plant managers and how many relegated the survey to someone else who is more junior. To address this concern, a survey question that asked for the title of the survey respondent was examined in depth. $79 \%$ of the respondents had a senior title of plant or operations manager. $11 \%$ had a more junior title such as, production manager; and $10 \%$ of the respondents did not provide information about their title.

Scott's Directory of Manufacturing (Group, 2007) was used to identify plants from each of the three industries in Canada. This research followed Dillman's (2000) five-point contact protocol: an initial introductory telephone contact; then two waves of postal surveys separated by a fax reminder; and a final telephone call to encourage participation. The survey was available in both English and French, and either a paper or on-line version could be completed and returned. This practice has been used in recent operations management research to help increase response rate (Johnson et al., 2007).

The data for this survey was collected over a six-month period ending in early 2008. To increase the likelihood that the plant would have at least some systems in place to manage social issues, plants with a minimum of 100 employees were targeted. A total of 1,209 surveys were distributed (574, 300 and 335 plants in the food, chemicals and transportation industries, respectively). In total, 42 were removed because the survey was undeliverable, or the facility was no longer in business or not a manufacturing plant. Another 42 surveys were returned with virtually no responses; and these surveys were removed from further analysis. Thus, 307 completed surveys were received, yielding an effective response rate of $25 \%$. To examine 
possible non-response bias, the respondent plants were compared to the pool of non-respondents in terms of sales, industry, and number of employees (Lessler and Kalsbeek, 1992). Early and late respondents were compared using the same criteria (Armstrong and Overton, 1977), as well as the survey technology (i.e., mail versus internet). No evidence was found that the respondents were not representative of the target sample. List-wise deletion was used for responses that had missing data.

\section{Scale Validation}

\section{Supplier socially responsible practices}

A key objective of this research was the development of a new set of scales to characterize the use of socially responsible practices in the supply chain. A five-step approach was employed. First, the literature base was reviewed to identify the items that would be necessary to form the constructs in question. Five major sources provided the items used in the survey (Klassen and Vachon, 2003; Carter and Jennings, 2004; Fairtrade, 2007; Jantzi, 2008; Social Accountability International, 2008). Second, the survey was pretested with five business managers and seven academics to assess face and content validity of the items, and improve readability. Within the questionnaire, the items were presented by scale rather than mixing the items for the various measures (Forza, 2009). Third, reliability was assessed for each individual construct, i.e., Cronbach's alpha (Segars, 1997). Fourth, Confirmatory Factor Analysis (CFA) was conducted across the related constructs for supply chain structure, and then supplier socially responsibility practices (O'Leary-Kelly and J. Vokurka, 1998). Finally, discriminant validity was assessed both for the items within a set of constructs (i.e., items within a construct are expected to be more highly correlated than those between constructs), and between pairs of constructs (constrained versus unconstrained CFA models). 
Four dimensions of supplier socially responsible practices were examined: supplier human rights, supplier labour practices, supplier COC, and supplier social audits. Supplier human rights measures the extent to which practices are in place to reduce the possibility that suppliers employ vulnerable groups of people, such as children. Supplier labour practices assesses the conditions in which employees perform their duties, and how an employer contributes to the overall welfare of employees. Supplier codes of conduct (COC) measures the extent to which specific procedures are explicitly spelled out by the focal firm to ensure that suppliers adhere to ethical expectations. Finally, the supplier social audits measures the degree to which suppliers are monitored by the focal firm to ensure their adherence to social expectations.

The values of Cronbach's alpha for the scales were $.96, .95, .82$, and .92 for supplier human rights, supplier labour practices, supplier COC, and supplier social audits scales, respectively. Appendix 1 presents the estimates and the model fit statistics for the CFA estimates for the four

final supplier socially responsible practices constructs that were used in the analysis; all were within acceptable ranges.

\section{Supply chain structure}

As previously discussed, three dimensions for supply chain structure were conceptualized as being critical for supplier socially responsible practices: transparency, dependency, and distance. Cool and Henderson (1998) developed a set of scales that examined supply chain dependency by examining two related aspects of buyer-supplier dependency. Drawing from this work, two multi-item scales were developed to assess the degree to which the focal firm was dependent on its suppliers and customers (Appendix 2). 
The transparency construct was divided into two sub-dimensions that attempted to capture the degree to which the plant perceived that an end-user (i.e., not necessarily the immediate, next-tier customer) was aware of both the focal firm's product and process. One sub-dimension dealt with the end-user knowledge of the supply chain, while the other dimension dealt with product visibility as perceived by the focal firm (Appendix 2). As with the previous set of constructs, the literature provided a basis for all of the items that were used in the scales and their formation (Cool and Henderson, 1998; Tapscott and Ticoll, 2003; New, 2004). Furthermore, these items were tested and refined to help ensure consistency and validity.

Cronbach's alpha values for these scales were acceptable, at .81, .87, .85 and .77, for supplier dependency, customer dependency, end-user knowledge of supply chain and product visibility, respectively. All general fit statistics for the CFA models also were within acceptable limits. Third, individual items were more highly correlated within their respective scales than between scales, providing evidence of discriminant validity. Finally, the fit of the unconstrained model was significantly better than for the constrained model, further supporting discriminant validity in the CFA model.

Finally, measures for distance were operationalized across three sub-dimensions: geographical, cultural and organizational distance. To measure the first two dimensions of distance, respondents provided the extent to which their primary suppliers were located in six different regions: Canada; United States; Latin America, including Mexico; Europe; Asia, including Russia, India, and China; and Africa. The items for each plant were scaled to equal one; these six metrics then served as weights applied to the different regions to estimate the weighted distance (either geographical or cultural) between the plant in Canada and its supply base. An 
analogous set of weights was also generated for the plant's customer base. Finally, to estimate the overall weighted geographical distance for the supply base, the regional weights were multiplied by the haversine distance (i.e., distance between two points on a sphere) between Canada and the geographic center of that particular region (Vincenty, 1975). While this metric has potential weaknesses, it provided a reasonable sense of the distances that must be managed between suppliers and customers. Additional sensitivity analysis using different geographic centers for a region did not reveal any significant differences in the parameter estimates of the regression models.

For cultural distance, the difference between Canada and each of six regions was estimated using a weighted average of the difference for each of four dimensions of culture (Hofstede, 1980), as done by others (Kaufmann and Carter, 2006). Finally, the overall weighted cultural distance for the supply base was estimated using the regional weights described earlier:

$$
C D_{J}=\sum_{i=1}^{4} \sum \sum I_{i j}-I_{i p}^{2} / V_{i} / 4 C D_{J}=\sum_{i=1}^{4}\left\{\left(I_{i j}-I_{i p}\right)^{2} / V_{i}\right\} / 4
$$

where $I_{i j}=$ the index for the $i^{\text {th }}$ cultural dimension and the $j^{\text {th }}$ region, $V_{i}=$ the variance of the index of the $\mathrm{i}^{\text {th }}$ dimension, $\mathrm{p}=$ Canada's score on the dimension, $\mathrm{CD}_{\mathrm{j}}=$ the cultural distance of the $\mathrm{j}^{\text {th }}$ region from Canada. An analogous cultural distance measure was estimated for the customer base.

Lastly, organizational distance was assessed based on the number of firms in the supply chain between the focal plant and the final end-user, and the focal plant and the primary basic raw material supplier. These two items were combined into a single overall measure of the total length of the supply chain (i.e., number of tiers). A related metric was estimated on the focal 
plant's relative upstream positioning in the supply chain, i.e., a higher value means further upstream, ranging from 0 (i.e., focal plant is the end-user) to 1 (i.e., focal plant is the raw material supplier). The correlation between the overall and relative measures was low, at .097; providing evidence that these two metrics assessed two distinct constructs.

\section{Assessment of social desirability}

Social desirability refers to a potential bias that might be introduced if respondents answer questions consistent with perceived social expectations (i.e., political correctness) or a desire to please the survey administrator. To address this issue, respondents were asked to give their responses to the questions about the practices at their plant, not their personal practices or beliefs. This subliminal technique has been used in the past to help reduce social desirability bias (Rudelius and Buchholz, 1979).

In addition, an accepted scale was used to assess the degree of social desirability and its impact on responses. A shortened form of the Crowne-Marlow Social Desirability Scale (Crowne and Marlowe, 1960), X2 (Strahan and Gerbasi, 1972); further validated by Fischer and Fick, (1993) was tested against scales measuring the four dimensions of supplier socially responsible practices. Ideally, a low, non-significant correlation is expected, as was found here; thus no evidence of social desirability bias was found.

\section{RESULTS}

A series of linear models was used to examine the relationship between the structure of the supply chain and the use of the four supplier socially responsible practices. Table 1 presents the descriptive statistics and correlation table of all the variables used in the regressions. Each 
regression model also controlled for industry, firm sales, unionization level and the degree of plant-level responsibility for supplier policies. The results are reported in Table 2.

Insert Tables 1 and 2 here

Support for H1 was found in all four of the models; higher levels of transparency were related to higher levels of supplier socially responsible practices. More specifically, as product visibility increased, the use of supplier human rights $(\mathrm{p}<.01)$, supplier labour practices $(\mathrm{p}<.05)$, supplier COC $(\mathrm{p}<.05)$, and supplier social audits $(\mathrm{p}<.01)$ increased. In contrast, support for H2b was very limited, with some evidence of greater use of supplier human rights $(\mathrm{p}<.1)$ as customer dependency increases. No evidence of a relationship between supplier dependency and the use of supplier social practices was found (H2a).

Finally, multiple dimensions of distance also were significantly related to the use of supplier socially responsible practices (H3). Thus, several important relationships emerged. First, as the organizational length of the supply chain increased, the use of supplier labour practices, COC and social audits increased. Moreover, being positioned further upstream in the supply chain (i.e., closer to raw material sourcing) also was related to greater use of supplier COC. However, contrary to expectations, as the weighted geographical distance for suppliers increased, the use of supplier COC decreased. Finally, no evidence was found that customer geographic or cultural distance was related to the use of supplier socially responsible practices.

Additional diagnostics were considered to assess any potential impact of collinearity. Only two independent variables had a correlation coefficient greater than 0.3 , suggesting few concerns. 
Further modeling assessed the impact of deleting individual variables, and the regression results changed little.

\section{DISCUSSION}

\section{Drivers of Socially Responsible Practices}

The paper identified a number of drivers that increased the adoption of socially responsible practices. First, one form of transparency, namely product visibility, was significant across all models. Thus, the use of multiple supplier socially responsible practices is linked to greater product visibility. Potentially, firms might engage in these practices to proactively protect their firm reputation and brands. For example, firms that make greater use of a COC have a more formalized process in place for the manner in which they interact with suppliers. This formalized process helps to educate both managers in the focal firm and its suppliers about socially acceptable (but culturally bound) procedures. Furthermore, with greater use of supplier social audits, firms follow up with their suppliers to ensure adherence. Collectively, these practices decrease the probability that suppliers are engaged in improper practices, such as using child labour, which could harm the firm and the value of its brands.

It is important to consider how this might be interpreted in light of prior literature. Tapscott and Ticoll (2003) argued that firms would no longer be able to hide from their customers in this new technology age. This research provides empirical evidence to support this perspective; firms engaged in supplier socially responsible practices when customers were aware of the firm and its brand. However, little evidence was found to support the notion that the structure of the supply chain significantly impacted the adoption of supplier socially responsible practices. Perhaps this occurred because customers might not yet fully comprehend the notion of supply chains, or have little interest in understanding the flow of products through many firms on its way to the end- 
user. Naturally, this might evolve and change over time as communication technology further advances, and customers come to expect clear reporting and traceability of products through multiple firms in complex supply chains.

Only limited support was identified for the relationships between dependency and the various supplier socially responsible practices. In particular, for human rights, greater customer dependency did encourage the greater use of supplier practices. To some extent, one might argue that this is the most basic form of supplier socially responsible practices, and the first hurdle that end-users are likely to worry about in a developed market, such as Canada. This concern is passed backwards up the supply chain - at least to focal firms that are highly dependent on specific customers. There are several factors that might explain the limited findings for the other practices. First, dependency may have much less influence on other socially responsible practices than do related constructs, such as the degree of power or control exercised by a focal firm over supply chain partners. Second, the costs of implementing these practices were not measured, and likely vary by supply chain context, which may outweigh the impact of dependency.

On the other hand, distance in the supply chain did impact the adoption of supplier socially responsible practices. Organizational distance was a dimension of distance that was important in the majority of the models. First, the relationship between the total length of the supply chain and supplier socially responsible practices was positive. All other aspects being equal, having more tiers in the supply chain translates into greater complexity and greater uncertainty. Establishing systems to formally develop supplier socially responsible practices can attenuate the range and number of concerns that must be managed. For example, supplier social audits is a 
clear mechanism to actively monitor a global supply base and ensure that far-flung suppliers are acting in ways that are consistent with the firm's own standards.

This finding can be linked to prior research in operations management that has studied supplier monitoring. The practices that make up the social auditing dimension of supplier socially responsible practices were heavily borrowed from the environmental management field (Klassen and Vachon, 2003; Zhao et al., 2007), where some work has considered the impact of the length of the supply chain on the adoption of supplier audits (Kovács, 2008). Thus, the findings of this research can potentially be transferred to environmental management research. More generally, firms might be expected to establish increasingly sophisticated audit systems for their suppliers' practices and performance (be they social, environmental, quality, etc.) as the supply chain increases in length.

At a superficial level, one might argue that stronger collaboration with suppliers might remove the need for auditing and monitoring of suppliers (Vereecke and Muylle, 2006; de Leeuw and Fransoo, 2009). However, even in the presence of collaboration, a focal firm must clearly signal both their concern and commitment to particular standards of performance, and not simply "trust" that their expectations are met. Thus, while auditing is undoubtedly important in relatively short supply chains, its importance grows as the supply chain lengthens and increases in complexity. Both trust and open communication is likely to decline as the number of tiers between the focal firm and a supplier increases. Thus, auditing provides a tangible indicator of the importance of appropriate supplier behaviour, while also exercising greater control over an extended supply chain. Future research might more clearly explore the relationship between collaboration, auditing and supply chain length to better disentangle the role and importance of 
each factor. For example, collaboration might attenuate, to some degree, the need for auditing; alternatively, auditing might encourage collaboration as both the focal firm and the supplier become more aware of the other party's needs, priorities and capabilities.

The empirical analysis clearly indicated that firms that are closer to raw material extraction are more likely to put supplier COC in place. Several possible explanations support this outcome. First, as a focal firm gets closer to raw material sourcing, it is conceivable that the firm is more likely to be directly buying from plants and operations in developing countries. Depending on the degree of legal enforcement present, local suppliers may be tempted to cut corners, or in fact, see little reason to meet vague expectations imposed by foreign buyers. Thus, COC ensure that the supplier is well aware of what is expected, and the consequences of not meeting those expectations. Second, several certifications gaining widespread adoption, e.g., Fairtrade, are related to raw material extraction or supply. These certifications can serve as proxies for COC. In contrast, certifications have not been applied to the same degree for exporters, distributors and downstream processors. However, one might expect this to change over time as the management of social issues in the supply chain broadens and deepens; thus, new certifications might extend Fairtrade principles further downstream in the supply chain (Roberts, 2003).

However, at least one finding appeared to be counter-intuitive: as geographical distance increased, the focal firm was less likely to establish supplier COC (despite the points raised in the previous paragraph). One possible reason is that as the geographical distance increases, the number of repeated interactions between a focal firm and individual suppliers might decrease; furthermore, any interactions might be more transactional in nature, and there are fewer 
opportunities for unethical dealings between the supplier and the focal firm. Thus, larger distances are traded-off against position in the supply chain.

\section{Managerial Implications}

There are a number of reasons for operations managers to adopt supplier socially responsible practices and to invest time and financial resources into these practices. Overall, two possible rationales underpin these decisions: seeking new opportunities to position a firm's products and brands; and minimizing the risks of criticisms and concerns from NGOs, the public and customers. Moreover, developing supplier socially responsible practices can help mitigate the negative outcomes of unexpected events and/or revelations.

Managers with valuable, highly visible brands do not want their brand images tarnished by improper practices in the supply chain. Therefore, these managers are more likely to invest in practices that might help to protect their product's brand. By putting these supplier socially responsible practices in place, it is less likely that improper practices in the supply chain would occur. Furthermore, operations managers that currently have supplier socially responsible practices in place can promote these practices to their customers to further differentiate the firm and give it more of a competitive advantage. This research found that supply chain visibility drove the adoption of supplier socially responsible practices. By extension, firms with welldeveloped practices can launch educational programs for consumers to illustrate the tangential social benefits that have been embedded in their products and supply chains. Much like Starbucks, educational campaigns can both influence customer purchase behaviour and create conditions that force competitors to match their actions. But not all competitors are likely to have the management capabilities or economies of scale essential to replicating socially 
responsible practices in a cost effective manner. Thus, socially responsible practices simultaneously achieve social gains, blunt potential criticism, and erect barriers for potential competitors.

The number of tiers in the supply chain also influences what operations managers did to address social concerns. As a supply chain becomes longer, operations managers put more procedures and policies in place, such as audits, to manage supplier adherence to social expectations (Mamic, 2005). However, as a firm is positioned farther downstream, it becomes more difficult to first, identify specific suppliers (e.g., try to name the particular third-tier supplier providing the iron ore for the steel casing of a computer), and second, to realistically track working conditions (e.g., labour) used for manufacturing particular materials and parts in organizationally distant suppliers. Moreover, some would argue that COC are less relevant as the firm's responsibility diminishes with more organizational hand-offs (New, 2004). Additionally, firms that are closer to the commodity sourcing or extraction stage have demonstrated greater use of supplier COC, which in turn, can have a positive impact on the supply chain (Kovács, 2008).

It is interesting to look at the level of involvement of the four types of supplier socially responsible practices. Admittedly, while the data gathered was perceptual and subjective in nature, the relative use (i.e., rank order) of each practice can be assessed. The survey results indicate that the level of involvement in supplier COC was the highest, followed by supplier human rights, then supplier labour practices, and finally supplier social audits. Thus, we see evidence for progressive development from internal (i.e., COC involve both the buyer and supplier), to supplier-oriented (i.e., human rights and labour practices), to verification of practice (i.e., auditing). In essence, operations managers are beginning to address social issues by trying 
to get their own operational practices in order, as supplier COC ensure that buyer's employees have procedures and practices to deal with suppliers ethically. Additional practices then engage and push suppliers to improve their human rights and labor practices. Finally, operations managers would put supplier social audits in place to ensure that suppliers are adhering to these new social practices.

\section{Limitations}

There were several limitations to this research. First, the surveys were only administered to Canadian manufacturing plants. While the general findings of this study are expected to be generalizable to firms in other developed countries, the extent and strength of particular relationships might vary from country to country. Also, costs of the four socially responsible practices were not assessed, and are likely to influence both the degree and rank order of the constructs. The resources to implement supplier socially responsible practices might also vary based on the overall degree of competitiveness and profitability of particular industries or regions. Thus, supplier social auditing in China might be much less expensive for a Japanese firm than for a Canadian firm, thereby influencing its adoption. Similar issues arise with the importance of particular practices to focal firms in different countries, as American customers might view their relative importance quite differently than, for example, European customers.

While the research design tested for the potential of social desirability, it cannot be entirely ruled out. Further research along similar lines by others might provide additional insight into its relative impact on data collection. 


\section{CONCLUSIONS}

One of the main contributions of this research is the development of an operations perspective of social issues in the supply chain. In contrast to earlier research, practices related to social issues were clearly delineated from the sustainable development literature, in general, and the environmental management literature, in particular. Prior work also has tended to employ proxies, such as accounting measures, which are difficult to translate to operationally relevant management levers. Based on prior literature, corporate best practice and the foundational work of international standards organizations, a set of operations-based scales was developed and empirically validated using a large-scale survey of three industries in Canada. Four dimensions of supplier socially responsible practices were identified: supplier human rights; supplier labour practices; supplier codes of conduct; and supplier social audits. These scales also represent an initial step toward quantifying the costs and benefits of developing socially responsible practices and assessing management attention and capabilities in this area.

Second, much of operations and strategy is concerned with the design of the supply chain. Thus, when considering a new area such as social issues, key supply chain variables were expected to influence the development and use of socially responsible management practices. To that end, relationships between supply chain structure and supplier practices were tested empirically. Evidence pointed to two factors in supply chain structure - transparency and distance - being related to supplier socially responsible practices. For transparency, the degree of product visibility to end-users was significantly related to greater use of multiple dimensions of supplier socially responsible practices. Thus, firms can be construed to be using these practices to either enhance or protect the firm's brand and reputation. Also, organizational distance was related to supplier socially responsible practices, with more tiers in the supply chain being linked to greater 
use of these practices, which help better manage societal expectations in the supply chain. Finally, as the plant was positioned further upstream in the supply chain (closer to raw material extraction), it was more likely to have supplier codes of conduct in place.

\section{Future Research}

The development of these scales provides an empirical basis for further scale refinement by other scholars characterizing socially responsible practices. This research focused very explicitly on supplier practices. However, suppliers capture only half of the supply chain. Customers too are expected to be instrumental, and the impact of customer expectations should be measured and modeled. Expectations might be captured directly, using surveys of representative customers, or indirectly, using panels of experts. Ideally, such survey work would be complemented by case studies that examine socially responsible practices across the entire supply chain. Both forms of empirical research would provide further details about new (or related) constructs, the nature of specific relationships, and the likelihood of different performance outcomes. For example, some practices such as social auditing might be strongly related to risk reduction, while others, such as supplier labour practices might be linked to opportunities, e.g., increased productivity.

Additionally, a survey could be conducted on the general population to explore how typical consumers assign responsibility for social issues in supply chains for common products, like food or manufactured durable goods. Possibly, operations managers need only take responsibility for some social issues a single tier back in the supply chain, for example worker conditions, while other issues, such as product safety, encompass all tiers in the supply chain. Moreover, responses of consumers could be compared against those from plant managers to understand the degree of consistency or alignment. Collectively, understanding both the 
assignment and scope of responsibility can assist managers with identifying high priority areas, and focusing the investment of limited resources.

\section{REFERENCES}

Armstrong, J.S., Overton, T.S. (1977). "Estimating Nonresponse Bias in Mail Surveys." Journal of Marketing Research 14 (3), 396-402.

Banet, A.G. (1976). "Organizational Distance: A Concept for the Analysis and Design of Organizations." Group \& Organization Studies 1 (4), 496-497.

Bansal, P., Hunter, T. (2003). "Strategic Explanations for the Early Adoption of ISO 14001." Journal of Business Ethics 46 (3), 289-299.

Baumann, H., Boons, F., Bragd, A. (2002). "Mapping the Green Product Development Field:

Engineering, Policy and Business Perspectives." Journal of Cleaner Production 10 (5), 409-425. Brundtland, G.H. (1987). Our Common Future/World Commission on Environment and Development, Oxford University Press, Oxford.

Carr, A., Kaynak, H., Hartley, J., Ross, A. (2008). "Supplier Dependence Impact on Supplier's Participation and Performance." International Journal of Operations and Production Management 28 (9), 899-916.

Carter, C.R. (2000). "Ethical Issues in International Buyer-Supplier Relationships: A Dyadic Examination." Journal of Operations Management 18 (2), 191-208.

Carter, C.R., Jennings, M.M. (2004). "The Role of Purchasing in Corporate Social Responsibility: A Structural Equation Analysis." Journal of Business Logistics 23 (1), 145-186. Carter, C.R., Rogers, D.S. (2008). "A Framework of Sustainable Supply Chain ManagementMoving toward New Theory." International Journal of Physical Distribution \& Logistics Management 38 (5), 360-387.

Carter, J.R., Jennings, M.M. (2002). "Logistics Social Responsibility: An Integrative Framework." Journal of Business Logistics 23 (1), 145-180.

Castka, P., Balzarova, M.A. (2008). "The Impact of ISO 9000 and ISO 14000 on Standardisation of Social Responsibility - an inside Perspective." International Journal of Production Economics 113 (1), 74-87.

Choy, K.L., Lee, W.B. (2003). "A Generic Supplier Management Tool for Outsourcing Manufacturing." Supply Chain Management: An International Journal 8 (2), 140-154. Cool, K., Henderson, J. (1998). "Power and Firm Profitability in Supply Chains: French Manufacturing Industry in 1993." Strategic Management Journal 19 (10), 909-926.

Crowne, D.P., Marlowe, D. (1960). "A New Scale of Social Desirability Independent of Psychopathology." Journal of Consulting Psychology 24 (4), 349-354.

De Leeuw, S., Fransoo, J. (2009). "Drivers of Close Supply Chain Collaboration: One Size Fits All?" International Journal of Operations \& Production Management 29 (7), 780-739.

Dillman, D.A. (2000). Mail and Internet Surveys: The Tailored Design Method, Wiley, New York. 
Dixit, A.K., Nalebuff, B.J. (1991). "Thinking Strategically: The Competitive Edge in Business." Politics, and Everyday Life, WW Norton.

Elkington, J. (1997). Cannibals with Forks: The Triple Bottom Line of 21st Century Business, Capston Publishing, Oxford.

Emmelhainz, M.A., Adams, R.J. (1999). "The Apparel Industry Response To "Sweatshop"

Concerns: A Review and Analysis of Codes of Conduct." Journal of Supply Chain Management 35 (3), 51-57.

Fairtrade, L.O.I. (2007). "Fairtrade Certification." Retrieved December 10, 2007, from http://www.fairtrade.net/.

Fischer, D.G., Fick, C. (1993). "Measuring Social Desirability: Short Forms of the MarloweCrowne Social Desirability Scale." Educational and Psychological Measurement 53 (2), 417424.

Forza, C. (2009). Surveys. In C., K. (Ed.) Researching Operations Management. New York: Routledge - Taylor \& Francis.

Graafland, J.J. (2002). "Sourcing Ethics in the Textile Sector: The Case of C \& A." Business Ethics A European Review 11 (3), 282-294.

Gri (2006). Sustainability Reporting Guidelines. Boston, Global Reporting Initiative, 94. Group, B.I. (2007). Scott's National Manufacturers: 20+ Employees Directory, Toronto. Grover, V., Malhotra, M.K. (2003). "Transaction Cost Framework in Operations and Supply Chain Management Research: Theory and Measurement." Journal of Operations Management 21 (4), 457-473.

Grow, B. (2005). The Debate over Doing Good. Business Week. 3947, 76.

Harrigan, K.R. (1985). "Vertical Integration and Corporate Strategy." The Academy of Management Journal 28 (2), 397-425.

Hofstede, G.H. (1980). Culture's Consequences, International Differences in Work-Related Values, Sage, New York.

Hofstede, G.H. (2001). Culture's Consequences: Comparing Values, Behaviors, Institutions, and Organizations across Nations, Sage Publications, Thousand Oaks.

Jantzi. (2008). "Jantzi Research." from http://www.jantziresearch.com/index.asp?section=12.

Johnson, P., Klassen, R., Leenders, M., Awaysheh, A. (2007). "Selection of Planned Supply Initiatives: The Role of Senior Management Expertise." International Journal of Operations \& Production Management 27 (12), 1280-1302.

Joynt, P., Warner, M. (1996). Managing across Cultures: Issues and Perspectives, International Thomson Business Press, London.

Kaufmann, L., Carter, C.R. (2006). "International Supply Relationships and Non-Financial Performance-a Comparison of Us and German Practices." Journal of Operations Management 24 (5), 653-675.

Klassen, R.D., Vachon, S. (2003). "Collaboration and Evaluation in the Supply Chain: The Impact on Plant-Level Environmental Investment." Production and Operations Management 12 (3), 336-352.

Koplin, J., Seuring, S., Mesterharm, M. (2007). "Incorporating Sustainability into Supply Management in the Automotive Industry-the Case of the Volkswagen Ag." Journal of Cleaner Production 15 (11-12), 1053-1062.

Kovács, G. (2008). "Corporate Environmental Responsibility in the Supply Chain." Journal of Cleaner Production 16 (15), 1571-1578. 
Krause, D.R. (1999). "The Antecedents of Buying Firms' Efforts to Improve Suppliers." Journal of Operations Management 17 (2), 205-224.

Lee, H.L. (2002). "Aligning Supply Chain Strategies with Product Uncertainties." California Management Review 44 (3), 106.

Lessler, J.T., Kalsbeek, W.D. (1992). Nonsampling Error in Surveys, John Wiley \& Sons, New York.

Maloni, M., Benton, W.C. (2000). "Power Influences in the Supply Chain." Journal of Business Logistics 21 (1), 49-73.

Mamic, I. (2005). "Managing Global Supply Chain: The Sports Footwear, Apparel and Retail Sectors." Journal of Business Ethics 59 (1), 81-100.

Martin, R.L. (2002). "The Virtue Matrix: Calculating the Return on Corporate Responsibility." Harvard Business Review 80 (3), 68-75.

New, S.J. (2004). The Ethical Supply Chain. In New, S., Westbrook, R. Understanding Supply

Chains: Concepts, Critiques and Futures. Oxford: Oxford University Press, pp. 253-280.

Nike, I. (2004). Corporate Responsibility Report, Fiscal Year 2004. Beaverton, OR.

O'grady, S., Lane, H.W. (1996). "The Psychic Distance Paradox." Journal of International

Business Studies 27 (2), 309-333.

O'leary-Kelly, S.W., J. Vokurka, R. (1998). "The Empirical Assessment of Construct Validity." Journal of Operations Management 16 (4), 387-405.

Pfeffer, J., Salancik, G.R. (1978). The External Control of Organizations, Harper \& Row New York.

Porter, M.E., Kramer, M.R. (2006). "Strategy and Society: The Link between Competitive Advantage and Corporate Social Responsibility." Harvard Business Review 85 (12), 14.

Reynolds, N.L., Simintiras, A.C., Diamantopoulos, A. (2003). "Theoretical Justification of Sampling Choices in International Marketing Research: Key Issues and Guidelines for Researchers." Journal of International Business Studies 34 (1), 80-89.

Roberts, S. (2003). "Supply Chain Specific? Understanding the Patchy Success of Ethical Sourcing Initiatives." Journal of Business Ethics 44 (2), 159-170.

Rudelius, W., Buchholz, R.A. (1979). "What Industrial Purchasers See as Key Ethical Dilemmas." Journal of Purchasing and Materials Management 15 (4), 2-10.

Segars, A.H. (1997). "Assessing the Unidimensionality of Measurement: A Paradigm and Illustration within the Context of Information Systems Research." Omega 25 (1), 107-121. Settings, M. (2004). "Travail, Transparency and Trust: A Case Study of Computer-Supported Collaborative Supply Chain Planning in High-Tech Electronics." European Journal of Operational Research 153 (2), 445-456.

Seuring, S., Müller, M. (2008). "From a Literature Review to a Conceptual Framework for Sustainable Supply Chain Management." Journal of Cleaner Production 16 (15), 1699-1710. Social Accountability International (2008). Social Accountability International SA8000:2008. New York, NY.

Strahan, R., Gerbasi, K.C. (1972). "Short, Homogeneous Versions of the Marlowe-Crowne Social Desirability Scale." Journal of Clinical Psychology 28 (2), 191-193.

Tapscott, D., Ticoll, D. (2003). The Naked Corporation: How the Age of Openness Will Revolutionize Business, Free Press, New York.

Van Der Zee, D.J., Van Der Vorst, J. (2005). "A Modeling Framework for Supply Chain Simulation: Opportunities for Improved Decision Making." Decision Sciences 36 (1), 65-95. 
Vereecke, A., Muylle, S. (2006). "Performance Improvement through Supply Chain

Collaboration in Europe." International Journal of Operations \& Production Management 26

(11), 1176-1198.

Vincenty, T. (1975). "Direct and Inverse Solutions of Geodesics on the Ellipsoid with

Application of Nested Equations." Survey Review 23 (176), 88-93.

Williamson, O.E. (1979). "Transaction-Cost Economics: The Governance of Contractual

Relations." Journal of Law and Economics 22 (2), 233-261.

Zhao, X., Flynn, B.B., Roth, A.V. (2007). "Decision Sciences Research in China: Current Status, Opportunities, and Propositions for Research in Supply Chain Management, Logistics, and Quality Management." Decision Sciences 38 (1), 39-80. 


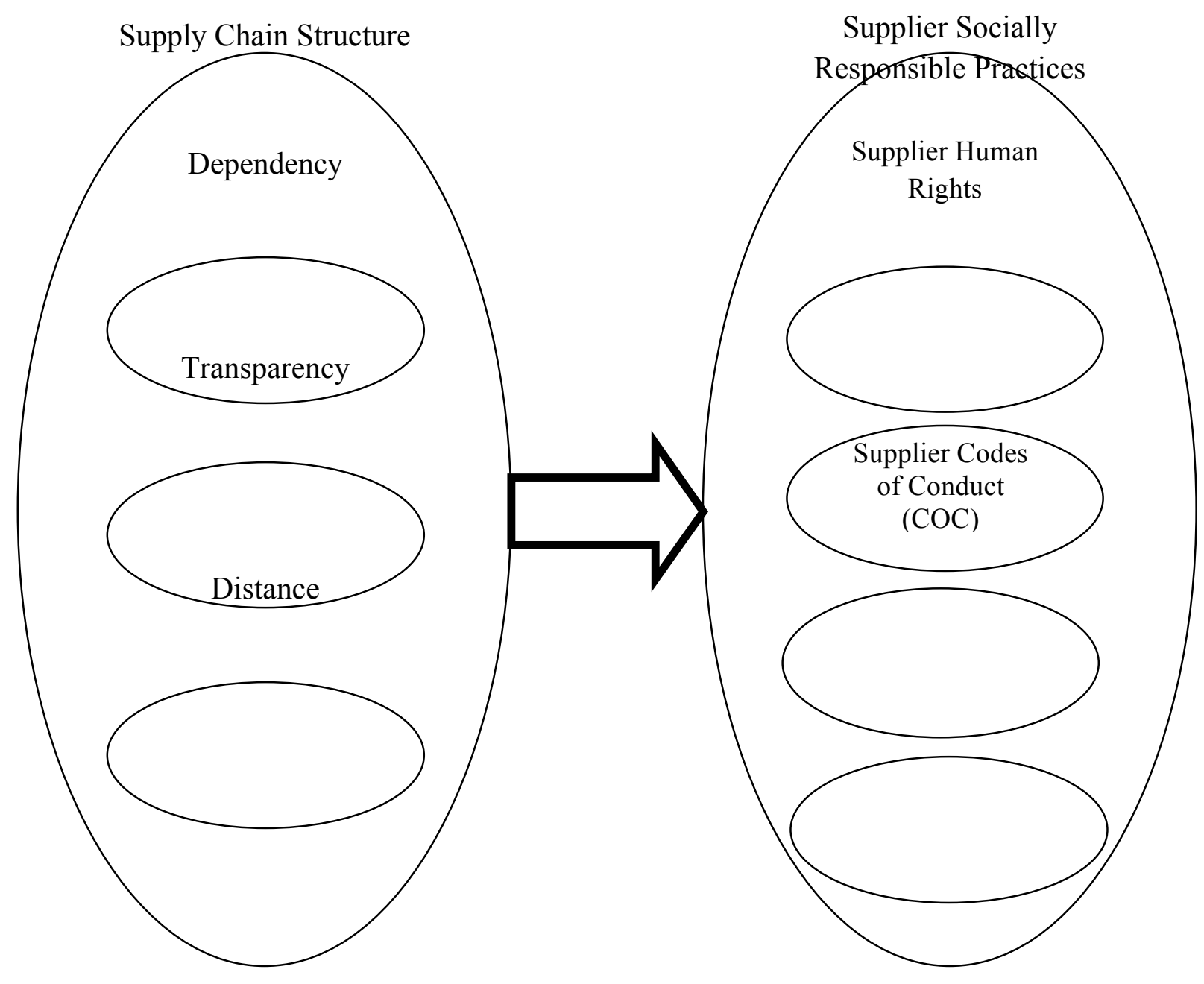

Figure 1-Conceptual Model 
Table 1 Descriptive Statistics and Correlation Table

\begin{tabular}{|c|c|c|c|c|c|c|c|c|c|c|c|c|c|c|c|c|c|c|c|c|c|}
\hline . & Variable & Mean & s.d. & 1 & 2 & 3 & 4 & 5 & 6 & 7 & 8 & 9 & 10 & 11 & 12 & 13 & 14 & 15 & 16 & 17 & 18 \\
\hline 1 & Chemical industry & .312 & .464 & & & & & & & & & & & & & & & & & & \\
\hline 2 & Transportation industry & .272 & .446 & -.412 & & & & & & & & & & & & & & & & & \\
\hline 3 & Firm sales & 3.438 & 1.253 & .106 & .022 & & & & & & & & & & & & & & & & \\
\hline 4 & Unionization level & .456 & .461 & .016 & -.149 & . 017 & & & & & & & & & & & & & & & \\
\hline 5 & Plant-level responsibility for supplier policies & 2.553 & 1.168 & -.169 & .047 & .009 & .110 & & & & & & & & & & & & & & \\
\hline 6 & End-user knowledge of supply chain & 3.403 & 1.441 & -.151 & .063 & .011 & -.019 & .042 & & & & & & & & & & & & & \\
\hline 7 & Product visibility & 4.748 & 1.845 & -.022 & -.043 & -.024 & -.027 & .020 & 469 & & & & & & & & & & & & \\
\hline 8 & Dependency on suppliers & 4.901 & 1.128 & .065 & .049 & .133 & -.139 & .044 & .035 & .040 & & & & & & & & & & & \\
\hline 9 & Customer dependency on plant & 4.408 & 1.337 & -.024 & .268 & .122 & -.128 & -.006 & 091 & -.018 & 281 & & & & & & & & & & \\
\hline 10 & Supplier geographical distance & .317 & .098 & .126 & .001 & 158 & .000 & -.134 & .038 & .105 & .069 & 019 & & & & & & & & & \\
\hline 11 & Supplier cultural distance & .294 & .273 & .147 & 177 & .174 & .014 & -105 & -.057 & .000 & .059 & .109 & .635 & & & & & & & & \\
\hline 12 & Total length of the supply chain & 3.921 & 2.950 & -109 & .134 & -.027 & -.065 & -.072 & -.128 & -.187 & .053 & .049 & .048 & .086 & & & & & & & \\
\hline 13 & Customer geographical distance & .291 & .092 & .059 & -.172 & .093 & .034 & -.056 & .061 & .088 & .161 & -.081 & .130 & -.019 & -.099 & & & & & & \\
\hline 14 & Customer cultural distance & .261 & 274 & .094 & .200 & 190 & -.012 & -.049 & -.064 & -.040 & 175 & .145 & .192 & .291 & .015 & .376 & & & & & \\
\hline 15 & Relative upstream positioning in the supply chain & .570 & 291 & -.014 & -.139 & .024 & .016 & .057 & -.088 & -.136 & 037 & .011 & -.134 & -.148 & -.122 & -.003 & . .049 & & & & \\
\hline 16 & Supplier human rights & 3.414 & 2.207 & .029 & .008 & .211 & .121 & -.063 & -.031 & .109 & .015 & .087 & .074 & .075 & .048 & -.012 & .063 & .046 & & & \\
\hline 17 & Supplier labour practices & 2.941 & 1.838 & .046 & .051 & .273 & . 097 & -.068 & .004 & .083 & .059 & .111 & .064 & .068 & 093 & .007 & 091 & .035 & .844 & & \\
\hline 18 & Supplier codes of conduct & 4.110 & 1.563 & .084 & -.070 & .326 & 134 & .058 & .026 & .087 & .063 & .061 & -.045 & .003 & .028 & .031 & .014 & .112 & .548 & .601 & \\
\hline 19 & Supplier social audits & 2.430 & 1.657 & -.044 & .015 & .209 & .139 & -.032 & .039 & .123 & -.014 & .058 & .062 & .041 & .089 & -.012 & .006 & -.008 & .748 & .803 & .609 \\
\hline
\end{tabular}

$|\rho| \geq .154$ are statistically significant at $p<.01$; and $|\rho| \geq .116, p<.05$. 
Table 2 Regressions Results

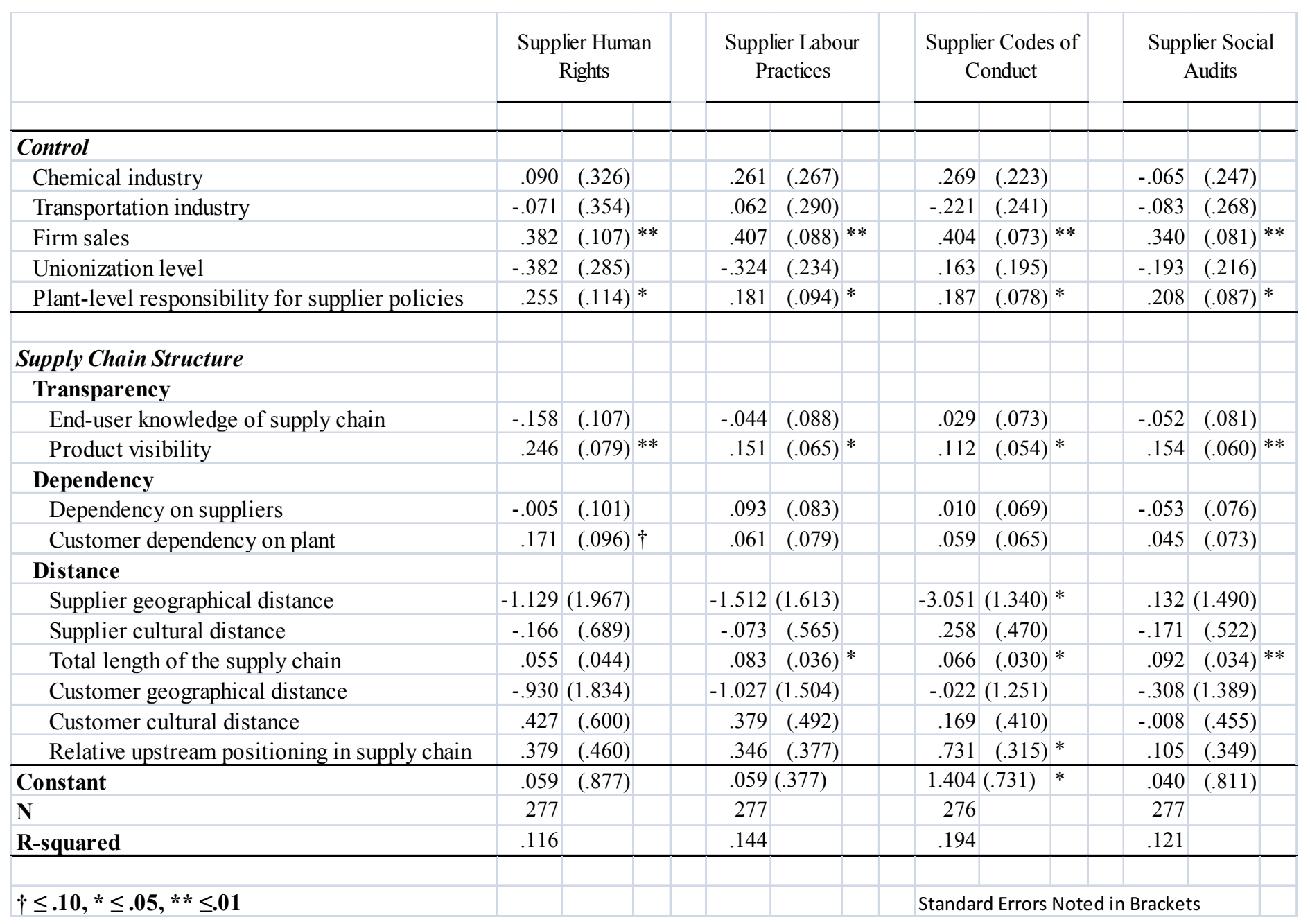




\section{Appendix 1 Supplier Socially Responsible Practices}

To what extent is your plant involved in the following policies and procedures related to your primary s uppliers? In general, our plant: (please circle a number for each item)

\begin{tabular}{|c|c|c|c|}
\hline & Variable & Item & Estimate \\
\hline \multirow{4}{*}{$\begin{array}{l}\text { Supplier } \\
\text { Human } \\
\text { Rights }\end{array}$} & HR1 & ensures that our suppliers do not use child labor & .956 \\
\hline & HR2 & $\begin{array}{l}\text { ensures that our suppliers do not use forced labor (e.g. prison } \\
\text { labor) }\end{array}$ & .975 \\
\hline & HR3 & $\begin{array}{l}\text { ensures that our suppliers pay their workers a living wage (i.e. a } \\
\text { wage that is above minimum wage) }\end{array}$ & .868 \\
\hline & HR4 & ensures that suppliers do not use sweatshop labor & .936 \\
\hline \multirow{6}{*}{$\begin{array}{l}\text { Supplier } \\
\text { Labor } \\
\text { Practices }\end{array}$} & SLC1 & $\begin{array}{l}\text { ensures that our suppliers have regulated over-time wage } \\
\text { policies (e.g. employees are paid a higher wage for over-time } \\
\text { work) }\end{array}$ & .890 \\
\hline & SLC2 & $\begin{array}{l}\text { ensures that our suppliers allow their employees to associate } \\
\text { freely (e.g. join or create a union) }\end{array}$ & .859 \\
\hline & SLC3 & $\begin{array}{l}\text { ensures that our suppliers do not discriminate against its own } \\
\text { workers }\end{array}$ & .925 \\
\hline & SLC4 & $\begin{array}{l}\text { ensures that our suppliers provide a healthy and safe working } \\
\text { environment for their employees }\end{array}$ & .854 \\
\hline & SLC5 & $\begin{array}{l}\text { ensures that our suppliers provide their employees with } \\
\text { protective equipment in hazardous areas }\end{array}$ & .864 \\
\hline & SLC6 & $\begin{array}{l}\text { ensures that our suppliers help improve the natural environment } \\
\text { in which they operate }\end{array}$ & .884 \\
\hline \multirow{5}{*}{$\begin{array}{l}\text { Supplier } \\
\text { Codes of } \\
\text { Conduct }\end{array}$} & SCOC1 & has a supplier code of conduct & .565 \\
\hline & $\mathrm{SCOC} 2$ & $\begin{array}{l}\text { has a management system to ensure that social expectations } \\
\text { affecting our suppliers are identified }\end{array}$ & .526 \\
\hline & $\mathrm{SCOC} 3$ & $\begin{array}{l}\text { ends relationships with suppliers that do not adhere to our code } \\
\text { of conduct }\end{array}$ & .834 \\
\hline & SCOC4 & $\begin{array}{l}\text { has a defined set of acceptable/ unacceptable behavior (e.g. } \\
\text { ethics statement) our employees must abide by }\end{array}$ & .851 \\
\hline & SCOC5 & $\begin{array}{l}\text { has ethical sourcing training programs for the purchasing } \\
\text { department }\end{array}$ & .747 \\
\hline \multirow{11}{*}{$\begin{array}{l}\text { Social } \\
\text { Audits }\end{array}$} & SA1 & $\begin{array}{l}\text { monitors our suppliers to ensure adherence to our social } \\
\text { expectations }\end{array}$ & .862 \\
\hline & SA2 & $\begin{array}{l}\text { conducts surprise visits to our suppliers to ensure adherence to } \\
\text { our social expectations }\end{array}$ & .884 \\
\hline & SA3 & $\begin{array}{l}\text { has specific audit procedures to ensure that our suppliers adhere } \\
\text { to our social expectations }\end{array}$ & .914 \\
\hline & $\chi^{2}$ & $=56.597$ & \\
\hline & $\mathrm{p}$-value & $=.149$ & \\
\hline & $\chi 2 /$ d.f. & $=1.204$ & \\
\hline & NFI & $=.976$ & \\
\hline & TLI & $=.994$ & \\
\hline & CFI & $=.996$ & \\
\hline & RMSEA & $=.030$ & \\
\hline & RMSEA CI & $=.000, .055$ & \\
\hline
\end{tabular}


For the following items, please describe your plant's relationship with your primary suppliers. In general, our plant (please circle a number for each item)

\begin{tabular}{|c|l|l|r|}
\hline \multirow{5}{*}{$\begin{array}{c}\text { Supplier } \\
\text { Dependency }\end{array}$} & SD1 & is greatly dependent on our suppliers & Estimate \\
\cline { 2 - 4 } & SD2 & has difficulty changing suppliers & .536 \\
\cline { 2 - 4 } & SD4 & requires a long time to change to new suppliers & .807 \\
\cline { 2 - 4 } & SD5 & winds it very costly to change to new suppliers & .868 \\
\hline
\end{tabular}

For the following items, please describe your primary customer's relationship with your plant. In general, our customers (please circle a number for each item)

\begin{tabular}{|c|l|l|r|}
\hline \multirow{3}{*}{$\begin{array}{c}\text { Customer } \\
\text { Dependency }\end{array}$} & CD2 & are greatly dependent on our plant & .549 \\
\cline { 2 - 4 } & CD3 & require a long time to change to new suppliers & .868 \\
\cline { 2 - 4 } & CD4 & find it very costly to change to new suppliers & .929 \\
\cline { 2 - 4 } & CD5 & will perform poorly if our plant doesn't perform well & .806 \\
\hline
\end{tabular}

The end-user is defined as the end customer that purchases and uses/consumes the product (the final link in the supply chain). For your primary product, please indicate the extent to which the end-user is aware of (please circle a number for each item)

\begin{tabular}{|c|c|c|c|}
\hline \multirow{4}{*}{$\begin{array}{c}\text { End-User } \\
\text { Knowledge } \\
\text { of Supply } \\
\text { Chain }\end{array}$} & SCS1 & how our product is manufactured & .787 \\
\hline & SCS2 & the type of raw materials that go into the product & .761 \\
\hline & SCS3 & where the raw materials are sourced & .865 \\
\hline & SCS4 & the structure of our supply chain & .817 \\
\hline \multirow{10}{*}{$\begin{array}{l}\text { Product } \\
\text { Visibility }\end{array}$} & PV1 & the name of the company that manufactures the product & .829 \\
\hline & PV2 & our brand name (product name) & .818 \\
\hline & $\chi^{2}$ & $=53.130$ & \\
\hline & $\mathrm{p}$-value & $=.219$ & \\
\hline & $\chi 2 /$ d.f. & $=1.155$ & \\
\hline & NFI & $=.965$ & \\
\hline & TLI & $=.993$ & \\
\hline & CFI & $=.995$ & \\
\hline & RMSEA & $=.026$ & \\
\hline & RMSEA & $=.000, .052$ & \\
\hline
\end{tabular}

